of the haemolysis in the fetus can be ascertained by measuring bilirubin-like pigments in the amniotic fluid.

But the most important indication for amniocentesis is the prevention of respiratory disease in the newborn. Liquor is usually taken by suprapubic puncture, but sometimes under ultrasound guidance; $1 \mathrm{ml}$ liquor is mixed with $1 \mathrm{ml}$ alcohol and shaken up. The amount of stable bubble formation tells us whether the fetus has surfactant or not, which will protect it from respiratory distress syndrome.

\section{FETAL MONITORING}

A further invasion into the privacy of the fetal world has taken place in the labour ward. To make labour safer for mother and fetus, monitors have been developed which can monitor the mother's contractions and record the fetal heart rate continuously. The nor- mal fetal heart rate is between 120 and 160 beats ner minute and the baseline should be changing all the time. Normally there is no relationship between the fetal heart and contractions. The following changes are associated with fetal distress. A fetal heart rate con. tinuously above 160 (tachycardia), or a heart rate continuously below 120 (bradycardia), suggests distress. Absence of baseline variability is an ominous sign. Often, especially near delivery, the fetal heart rate will decelerate with the contraction, but rccover immediately. This is due to compression of the head. However, when the deceleration continues after the contraction has ended, this is a particularly ominous sign of fetal distress.

When the obstetrician is worried about the fetal heart rate pattern, he will take a sample of blood from the fetal scalp and estimate its $\mathrm{pH}$ value. If the pH is below 7,2 this is almost always an absolute sign of a fetal problem; delivery should be at once expedited, usually by caesarean section.

\title{
REPORT ON CONGRESS PROCEEDINGS
}

\section{INTRODUCTORY COURSE IN NEURODEVELOPMENTAL THERAPY}

37 members attended this course. The lectures and demonstrations were given by members of the South African Neurodevelopmental Therapy Association. The first session discussed the properties of spasticity and the problems which spasticity poses to the physiotherapist. Current methods of controlling spasticity were analysed and the underlying philosophy of neurodevelopmental therapy was presented. The following session formulated the role played by the postural reflex mechanisms in determining normal motor development. The demonstration which followed showed how these postural reflex mechanisms can be utilized to obtain specific movement patterns in preparation for future skills as well as functional sequences of movement. The second half of the course was devoted to analysing the functional problems encountered with sitting standing and walking in different types of spastic patients. This section included an outline of how these problems develop as well as guidelines for treatment.

The workshop on upper extremity function was not held as planned owing to lack of support from Society members. Instead, an informal workshop was thrown open to occupational, speech and physical therapists and also teachers - and over 30 people attended two separate sessions, the first devoted to analysing upper extremity functions in the normal as well as in spastic and athetoid children and the second to discussing how to establish these functions in spastic children and in athetoid children.

S. Irwin-Carruthers

\section{WORKSHOP ON CLINICAL SUPERVISION}

The first session of the workshop which was chaired by Mrs. A. Mathias, Chief Physiotherapist of the Johannesburg Hospital complex, commenced with group formulation of aims and objectives of clinical supervision. The most important aspect that emerged from these groups was realisation that the clinical situation was the prime area for growth and development of the student.

By providing the right climate in the clinical situation, the student will be stimulated to think independently, to use her initiative and want to probe further and be responsible for her own learning. By teaching through demonstration, the supervisor will encourage acceptable standards of interpersonal relationships and professional values as well as reinforce in practice that which is taught in the classroom.

In two very competent talks given by students from the Universities of Cape Town and Stellenbosch, the need for better communication between student and supervisor was stressed. Claire Johnson urged far greater involvement of the supervisor in the clinical situation and felt that the student would only be able to learn, if she knew what was done correctly, what was unacceptable and how this could be changed.

Carin Hugo urged greater commitment on the part of the supervisor to provide assistance in all aspects of patient handling by demonstration and discussion, especially when the student is at the beginning of her clinical training. The student has the right to know what is good or bad in her patient management and must be given the chance to correct mistakes as well as specify her own problems. Evaluation must be objective and thorough and not be just a mark. Sho pleaded for supervisors to be enthusiastic about theif profession in order to stimulate the students.

In attempting to provide a meaningful learning experience in the clinical field, certain objectives for clinical supervisors were suggested by J. C. Beenhakker. These were teaching by demonstration in all areas of clinical competencies, co-ordinating class teaching and clinical practice, setting goals for achievement in that particular department, developing skills of problemsolving and providing constant and constructive feedback to the student. This feedback to the student is to point out where her strengths and weaknesses lie and whether the student has fulfilled the stated goals. The student should also be encouraged to assess the supervisor in order to bring about desirable change. The ideal supervisor should be competent in her own field. be available at all times, be able to communicate with the student and be sensitive to her needs.

In the second session under the Chairmanship of Miss M. J. Runnalls, Head of the Department of Physiotherapy of the University of Stellenbosch and Tygerberg Hospital, the emphasis was on the methods by which clinical supervision should be carried out. Although P. Bowerbank, Chief Physiotherapist at Kalafong Hospital, presented her talk in the form of a 
skit, the underlying message was a serious one. She stressed that the clinical area is a complementary part of the teaching situation and urged for greater cooperation between the supervisors and the academics. The skill of caring for the patient must be instilled by example and she felt that improved supervision would be brought about by greater knowledge of didactics.

Miss Runnalls spelled out the need for instructing clinical supervisors at the beginning of each year and following this up throughout the year. This would assist in defining the role and responsibilities of the supervisor and provide self confidence by self evaluation and peer audit. The supervisor should realize that it is a compliment to be assigned a student. She suggested that the supervisor should observe at the first treatment session and demonstrate if necessary and follow this up at weekly intervals. The supervisor must also check all documentation and registers as well as set specific tasks. A form of evaluation of students based on different data bases for third and fourth year students was discussed.

A second session of discussion by groups was then held to establish methods of clinical supervision.

From the papers read and the ensuing discussion, it was obvious that clinical supervision is far from deal. Even when objectives have been set both for the supervisor and the student and instruction in supervision provided, there appears to be a breakdown in communication between the student and her supervisor and the teaching staff. This means that either the objectives are not realistic or that they have not been understood by all parties concerned. To rectify this, further workshops should be held with participants coming from the academic staff, clinical supervisors, clinicians and the student body.

A further problem area is the manner of evaluating clinical competence. If the clinical situation is the primary one for learning of interpersonal, intellectual and technical competencies, then adequate and continuous feedback is required in all these areas. Each objective should be assessed and assistance given in improving weaknesses, together with praise for strengths. The student must also be given the opportunity to provide feedback to the supervisor as regards her methods of supervision in order to bring about desirable change.

In the final summing up, Mr. B. R. Slabbert, Head of the Department of Didactics at the Faculty of Medicine, University of Stellenbosch, touched upon three main problem areas. The first was the need for establishing aims and objectives by a person with thorough knowledge in the field concerned. These must then be given to the student and the supervisor must ensure that they are understood. Motivation was considered the most important cornerstone of learning in the clinical field as in any other field. Finally it was suggested that it is important to evaluate in the affective domain which is the most difficult of the three domains.

J. C. Beenhakker.

\section{BACKACHE AND THE PREGNANT PATIENT}

\section{LOUISE HACK* B.Sc. (Physio), Witwatersrand}

Few women pass through their pregnancy and puerperium without some backache symptoms. Unfortunately, gynaecologists seem impervious to the word "backache" from the lips of a pregnant woman and consider it part and parcel of having babies. Gynaecologists seldom refer their patients to physiotherapists, which causes a considerable amount of unnecessary suffering. For the pregnant patient (and her husband) it is very difficult to live with backache and the emotional effect of this continued discomfort can strain relationships within the family. Of course, there is a group of women who love their backaches and wouldn't part with them. They obviously need a different type of therapy from physiotherapy!

The causes of backache were discussed, but the lecture itself concentrated mainly on mechanical conditions, where the symptoms are due to malfunction of the joints and will respond to treatment directed towards correction of the mechanical impairment.

The combined effects of poor posture and hormonal influences were discussed. Ligamentous laxity, due to the effect of hormones, such as relaxin, occurs during pregnancy and predisposes towards lumbar stress and sacroiliac strain. Combined with the compensatory increased lumbar lordosis, due to the changed centre of gravity, the strain on these joints and ligaments is further increased.

\section{MANAGEMENT OF BACKACHE IN PREGNANCY}

This was discussed under the following headings:

1. Remove the cause where possible e.g. a sagging mattress, high-heeled shoes.

* Private Practitioner, Pretoria

$\dagger$ Summary of a paper read at Congress preceding 13th National Council Meeting 23-27 April 1979.
2. Posture re-education and strengthening exercises must be the first priority at ante-natal classes when patients come with backache. The basis of spinal control is the pelvic tilt. As a prophylactic measure. postural control should be taught to all patients at risk in the first trimester, i.e. ALL patients with a previous history of backache symptoms. Strengthening exercises for postural muscles must be taught and practised to prevent too much ligamentous strain as the pregnancy progresses. If these patients are taught good postural control, chances of backache developing are greatly diminished.

The first line of defence of any joint against injury or strain is ligamentous and when ligamentous support is deficient, as may occur in pregnancy, the muscles must complement ligamentous function. The most important factor in treating backache during pregnancy, is PREVENTION. The following muscle groups are exercised for this purpose: oblique, straight and transverse abdominal muscles; gluteal muscles; back extensors; psoas and side flexors.

Examples of suitable exercises were explained with attention being given to pelvic tilt in various positions and with progressions. All pelvic tilt exercises were done from mid-position to backward pelvic tilt position to prevent facet impingement and disc stress in an already lordotic lumbar spine. Many examples of strengthening exercises for postural muscles were shown. The choice of starting position and avoiding unilateral weight-bearing positions in patients with sacro-iliac strain were stressed. Exercises to be avoided were also shown. Quadriceps and gluteal exercises were included to strengthen the legs, thus preventing trauma to the back in lifting.

3. "Auto-manipulation" movements, where patients do the movements slowly and rhythmically and find the range and rate of movement that gives relief.

4. Ice Packs. 
5. The caring aspect of massage was emphasised.

6. Ultrasound was thought controversial in pregnancy.

7. 'Sam-Brown' supportive belt could be worn to support the sacro-iliac joints and stabilise the pelvic ring.

8. Manipulation was also thought to be controversial in pregnancy.

9. Education plays a vital part in the treatment routine. Patients must be taught how to carry over correct postural positions of the body in everyday activities. They must understand the anatomy and movements of the spinal column and pelvis in order to minimise unnecessary stresses and strains. Patients should be taught how to move from sitting to standing, or from lying to sitting; the correct sitting posture, standing positions and manner of lifting. Education must also prepare the patient for the post-natal period.

In conclusion positions of optimal comfort for exercise, sleep, relaxation, first stage labour and delivery were discussed. A thorough knowledge of each patient's condition is essential before exercises are commenced and the physiotherapist must make adaptations where necessary for each individual patient, always bearing in mind that injudicious exercise will do more harm than good.

\section{VALUE OF QUALITY OF MOVEMENT FOR PREGNANCY}

Most people are ignorant about their bodies and how they work. Many people are starved of movement as they do not participate in sport or organised exercise after leaving school. Various occupations, careers and nature encourage laziness or exercise inactivity. Marriage leaves even less time for sport. Thus most women are unfit at the beginning of pregnancy. Advancing pregnancy leads to increasing stiffness and unwillingness or inability to move. Exercise classes are put off, especially if people continue working. Labour comes as a surprise as it is physically harder than expected. Thus the mother is faced with post-natal recovery and adjustment, flabby muscles, an aching back and very little time. This vicious cycle can be prevented by organised, correct and regular movement.

To achieve fitness for labour, at least twelve weeks of ante-natal training is recommended, usually from 24 - 36 weeks, which leaves another 4 weeks for more exercise or rest, whichever is appropriate. Once pregnant women start exercising, they continue into labour. They feel better as aches and pains disappear, they relax and look better as they master correct movement, become co-ordinate and feel in control of their bodies. It is too late to wait until labour starts, when they feel stiff and inco-ordinate and have difficulty in performing the task.

Abdominal muscles work at an increasing mechanical disadvantage in pregnancy, thus exercises are performed in lying and posture control is stressed. One aims at normal movement checking abnormal or excessive movement and suggesting a suitable home routine. Any movement which is painful or uncomfortable is discontinued and possibly a different starting position is all that is required.

The exercise routine is followed by relaxation training, normal breathing changes expected in labour, pushing techniques, advice on bra's and breast care and problems encountered on taking the baby home.

Patients are familiarised with hospital routine on admission and taken on a tour of the labour and postnatal wards. Time for discussion and questions contributes to relaxation.

Exercises to music followed the short dissertation H. B. Kastell

\section{REPORT ON THE THIRTEENTH GENERAL MEETING OF THE NATIONAL COUNCIL}

The Thirteenth General Meeting of the South African Society of Physiotherapy was held in the Beattie complex of the University of Cape Town on $: 26$ and 27 April 1979. Forty delegates attended, the full voting strength being fifty-five. Several observers also attended.

The Chairman, Mrs. K. M. Levy, welcomed delegates and observers and gave a special word of welcome to Professor A. J. Brink, President of the South African Medical Research Council and Dean of the Faculty of Medicine at the University of Stellenbosch, and to $\mathrm{Mr}$. J. J. Craig, President of the South African Society of Physiotherapy.

Professor Brink gave the opening address, in which he outlined the activities of the Medical Research Council and challenged physiotherapists to involve themselves in research projects, particularly in the clinical sphere.

In delivering his Presidential address, Mr. Craig discussed the implications of first-contact physiotherapy practice and the importance of establishing the principle of first-contact practice. Mr. Craig's speech was published in the June issue of the Journal.

In her comprehensive Chairman's report Mrs. Levy commented first on the role which the National Committee of Representatives, which met for the first time in January 1976, had played in the affairs of the Society since its inception. The National Committee of Representatives, as a truly representative body, had not only acted in an advisory capacity to the National Executive Committee but had been the originator of several motions submitted to this Council Meeting for a final decision. One matter already passed by postal vote had enabled the Special Groups/Associations to elect representatives to and submit resolutions to Council, and at this point the Chairman welcomed the first official representatives of the Special Groups/Associations. Mrs. Levy also stressed the national interest and concern of the National Executive Committee and welcomed the fact that nominations for this Committee for the first time included the names of four nominees from outside the Transvaal.

The Chairman also outlined the work of the Professional Board over the last two years. Every effort is being made to have the prescription of the whole country in respect of the profession of physiotherapy re-gazetted. The list of acceptable registrable overseas qualifications has been completely revised and criteria for the acceptance for registration of additional qualifications have been laid down. There is also a move to establish a further set of criteria for post-basic courses of a shorter duration than one year which might contribute towards a credit system recognised by the Public Service Commission for salary purposes.

Although salary scales and conditions of service for physiotherapists in provincial employ were still far from satisfactory, the Chairman thanked the Depart- 